\title{
A quantitative evaluation of the effects of Ascophyllum harvesting on the littoral ecosystem
}

\author{
P. J. S. Boaden ${ }^{1} \&$ M. T. Dring ${ }^{2}$ \\ ${ }^{1}$ Queen's University Marine Biology Station; Portaferry, Co. Down, Northern Ireland, \\ and \\ ${ }^{2}$ Department of Botany, The Queen's University of Belfast; Belfast, Northern Ireland
}

\begin{abstract}
Little is known of the ecological effects of harvesting littoral algae although this is a worldwide commercial activity. In 1976 an attempt to establish harvesting in Strangford Lough, Northern Ireland, was opposed on mainly theoretical conservation grounds. The attempt began and stopped within a single small bay leaving a sharp boundary between cut and uncut areas. A subjective survey apparently confirmed the predicted loss of cryptic fauna, decline through predation and the resorting of interboulder sediment. In April 1979 the cut and uncut areas were examined in detail to determine whether any of these effects had persisted and were demonstrable scientifically. Beach and boulder transects and various other studies showed some increases in the cut area. There was significantly more Fucus, Enteromorpha and Ulva; Cirratulus (inhabiting Rhodochorton-bound sediment on boulder surfaces) had a greater biomass. Some changes in Littorina colour morphs were apparent. Sediment in the cut area was coarser and had significantly more crustacean meiofauna. Ascophyllum internodal length and lateral branching were increased but it still provided $20 \%$ less shore cover than in the uncut area. There were significant decreases in the cover of Cladophora on the sides of boulders and of Halichondria, Hymeniacodon and Balanus on undersurfaces. Indeed on the habitable underside of boulders total animal cover had been reduced by nearly two-thirds and the average number of species per boulder by one-third. It is concluded that Ascophyllum harvesting has a significant and persistent effect on shore ecology. Littoral algae are a valuable commercial asset but it is important that some fairly large intertidal areas should be left unharvested for general conservation purposes.
\end{abstract}

\section{INTRODUCTION}

Harvesting marine algae is now an important commercial activity on a worldwide basis. For example Alginate Industries Ltd., recently the subject of a take-over bid by Merck, utilize weed from Iceland, Ireland, Norway, Scotland, South Africa, South America and Tasmania. Their major alginate source is Ascophyllum nodosum harvested intertidally from north European waters. Alginate Industries are concerned with harvesting Ascophyllum in Ireland through Arramara Teoranta, a company owned jointly with the Republic's government, and less directly through supplies shipped to their Scottish factories by Clew Bay Seaweeds Ltd. of Newport, Co. Mayo.

Various studies of Ascophyllum in and around Strangford Lough and the Ards area of Co. Down were initiated by Dr. Dring in 1971 in response to information requests from the Ministry of Commerce (N. Ireland). This lough is the subject of one of the largest nongovernment sponsored conservation schemes in Europe. The National Trust for Places of 
Historic Interest or Natural Beauty owns or leases most of the intertidal zone and has acquired at least shooting rights over the remainder. Management is implemented through the Trust's Strangford Lough Wildlife Scheme. The area includes several important National Nature Reserves established, because of their marine biological interest, by the Conservation Branch of the Department of the Environment (N. I.). A working group convened by the Department recently recommended that "Strangford Lough should be conserved as a major recreational, education and wild-life resource" (Strangford Lough Working Group, 1978). It also suggested a possible mechanism whereby this might be accomplished (apparently in lieu of present Northern Ireland or U. K. legislation enabling declaration as a National Park).

Those concerned with conservation of the lough were perturbed by proposals first made in July 1976 to harvest between an eighth and a quarter of the Ascophyllum standing crop annually and alarmed when a trial cutting (not by the companies mentioned) was undertaken on a small area of shore without prior agreement of the National Trust.

The cutting was carried out in late August 1976 and extended about $180 \mathrm{~m}$ along the shore. The weed was mostly cut to within $10-15 \mathrm{~cm}$ of the base, rather shorter than normal harvesting practice. After removal of about 39.5 tonnes, cutting was stopped at the request of the National Trust along the boundary of one of its wild-life refuges. Inspection of the shore in mid-September showed loss from the cut area (in addition to the Ascophyllum removal) of attached weeds and colonial animals, loss of mobile animals such as winkles and blennies and loss of finer sediment particles-effects which, in addition to redeposition of silt and loss of abraded food source beyond the immediate cut area, had been predicted in earlier discussions. Further visits to the shore and to some regularly harvested areas in Co. Mayo led to inclusion of the following in a memorandum from Dr. Boaden to the Conservation Branch's Nature Reserves Committee. "The immediate effects of cutting are: (1) to remove the cut weed from the system; (2) to destroy the epifauna and flora; (3) to increase desiccation; (4) to increase predation; (5) to increase erosion; (6) to aid settlement of other species; (7) to stimulate bushy Ascophyllum growth ... There is thus a change in the balance of the community but at best there may be something like $80 \%$ recovery after the 4 years."

There is of course a danger that any subjective survey may be unduly though unintentionally biased by the observer's expectation of the result. Equally there is a danger that the statement that "There is no evidence to show that harvesting littoral seaweeds has any effect on shore ecology" (which is true because of the lack of published information) could be taken to mean that harvesting does in fact have little or no effect. To counter this confusion between the objective and subjective (whether scientific or grammatical) a quantitative investigation of the effects of this single cutting has now been undertaken.

\section{MATERIAL AND METHODS}

The work was carried out at Rathcunningham (Irish Grid J 53/55) about $2.5 \mathrm{~km}$ north of Killyleagh, Co. Down. Ten transect lines were established down the beach from HWN to LWN (mean neap range $2 \mathrm{~m}$ ). Five of these were in the area where Ascophyllum had been harvested and five in the unharvested area (Fig. 1). General shore cover was 


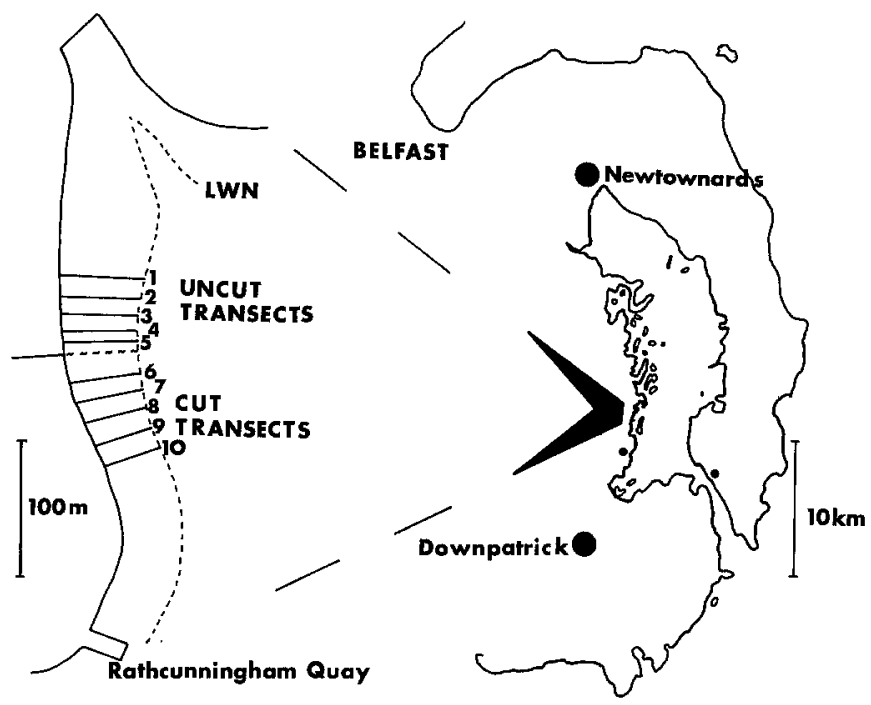

Fig. 1. Map of the Co. Down coastline and of the Rathcunningham shore showing sampling and transect locations. Line between 5 and 6 indicates refuge boundary

measured in the Ascophyllum zone on each transect line by a series of point transects taken horizontally at $0.5-\mathrm{m}$ intervals for $10 \mathrm{~m}$ up the beach starting at a point just above LWN. At each interval the weed and substratum touching a fine knitting needle at $10-\mathrm{cm}$ spaced points along a 1-m ruler were recorded.

Two boulders from either side of each transect line at a distance of about $2 \mathrm{~m}$ from LWN were studied in detail. The boulders chosen were the first found that were not particularly embedded and had a horizontal circumference of about $1 \mathrm{~m}$. A tape measure was placed around the maximum horizontal periphery of each boulder and a $1-\mathrm{cm}$ spaced point transect made, recording "hits" on Ascophyllum or "misses" (all other points). Five equally spaced point transects were taken across the top of each boulder to the horizontal peripheral line again recording hits or misses at $1-\mathrm{cm}$ intervals. The peripheral line was then chalked on each boulder, the Ascophyllum cut at its base and the boulders carefully transported to Portaferry.

In the laboratory the five upper surface transects were repeated on each boulder recording hits on Ascophyllum holdfasts, Cladophora, filamentous algae, Enteromorpha and Ulva, or bare boulder surface. Hits on other organisms were also noted and all attached animals on the upper surface counted. It was recorded whether each point was on "top" surface or "vertical" surface the latter being anything within $10^{\circ}$ of true perpendicular, those areas having been marked out before counting. The boulders were then turned over and ten equally spaced transects taken across the underside to the peripheral horizon. Hits were again recorded at each $1-\mathrm{cm}$ point each species being noted and Spirorbis, bryozoans and Balanus also recorded as apparently live or dead. Again each point was categorized as being in an uninhabitable area (had been buried or flat against the substratum - such areas were discoloured black or brown) or on lightly sloping surface (within $30^{\circ}$ of horizontal) or on steep surface $\left(>30^{\circ}\right)$. These areas had been outlined in chalk prior to counting. In addition to the point transects all large 
solitary organisms on each slope type were counted. Subsequently from the length and distance apart of boulder transect lines and the point data the total boulder area and percentage of each type of slope were determined. This enabled expression of the organism point transect data as percentage cover on each type of slope.

Various subsidiary studies were undertaken by students under general supervision of the authors. These were:

(a) Ascophyllum structure. Two hundred terminal portions of plants, half from the cut and half from the uncut area, were brought back from the boulder-sampling zones. The internode length, the number of dichotomies and the number of lateral branches were determined for both the terminal (1978-79) and penultimate (1977-78) internode of each portion.

(b) Patella populations and micro-algal abundance. Limpet density was estimated by systematically searching boulders and recording number per boulder. Ninety boulders were searched in the cut area and 232 in the uncut. The distance of each limpet from the nearest four Ascophyllum holdfasts was measured. Five replicate $10-\times 10-\mathrm{cm}$ areas of steep slope were scraped on two Patella inhabited and two Patella uninhabited boulders in both the cut and uncut areas and the chlorophyll present calculated after standard extraction (Jeffrey \& Humphrey, 1975). Three series of five $63.5-\mathrm{cm}^{2}$ areas of polythene sheeting were exposed for three days in the cut and uncut areas. The amount of chlorophyll that had settled or been produced on them was then determined. Two hundred Patella vulgata were collected from the cut area and 199 from the uncut, mean overall length was determined and population analysis attempted using arithmetic probability paper (Cassie, 1954).

(c) Littorina obtusata. Five fairly intensive collections of $L$. obtusata were made in the cut and in the uncut areas; unfortunately the collections were not standardised. However over 1300 winkles were brought back to the laboratory separated into 3 main colours (yellow, green and brown) and the maximum opercular width of each specimen measured.

(d) Carcinus maenus. Fifty boulders were turned over in the cut and in the uncut areas and the number of crabs below each recorded.

(e) Sediment and meiofauna. Samples were taken of the upper $5 \mathrm{~cm}$ of sediment at three locations in the cut and in the uncut areas (between transects 10 and 9, on 8 , between 7 and 6 ; between 5 and 4, on 3, between 2 and 1 - all at the same beach height as the boulder samples). At each location one large sample was taken for granulometric analysis and five $5-\mathrm{cm}^{3}$ samples for determination of meiofauna. The latter was extracted using two successive washes each after $7 \mathrm{~min}$ narcotization in $7 \% \mathrm{MgCl}_{2}$. The meiofauna was not identified except to major taxa.

(f) Worms and Rhodochorton. Two flat topped boulders with $100 \%$ Ascophyllum frond cover were selected from near LWN in each transect. The weed was parted and two $10-\times 10-\mathrm{cm}$ areas of surface scraped clean. Total wet weight and volume of each scraping was determined in the laboratory. The weed (mainly Rhodochorton) and worms (mostly Cirratulus cirratus) were separated from the sediment by washing over a $300-\mu \mathrm{m}$ sieve and the wet weight of weed and number and wet weight of worms determined after blotting. 


\section{RESULTS}

The beach transects showed some clear differences between the two areas (Table 1). In particular Ascophyllum cover was nearly $25 \%$ lower in the cut area whereas Fucus vesiculosus and Enteromorpha/Ulva density was higher. There appeared to be some difference in substratum between the areas although this was not quite significant at $5 \%$ level according to two-way analysis of variance ( $F$-test) using transect means.

Table 1. Mean \% cover in the Ascophyllum zone from harvested and unharvested areas at Rathcunningham. ${ }^{* *} p=0.01$

\begin{tabular}{|lrrrc|}
\hline & Uncut & Cut & $F$ & Significance \\
\hline Ascophyllum & 88.9 & 64.0 & 20.83 & $* *$ \\
Fucus vesiculosus & 0.9 & 10.8 & 18.07 & $* *$ \\
Cladophora & 7.7 & 8.3 & 0.02 & - \\
Enteromorpha/Ulva & 4.3 & 23.8 & 16.42 & $*$ \\
Ectocarpus & 7.1 & 7.9 & 0.04 & - \\
Boulder & 36.6 & 27.2 & 2.28 & - \\
Stone & 25.7 & 52.3 & 5.24 & - \\
Sand/Mud & 37.7 & 20.5 & 3.56 & - \\
\hline
\end{tabular}

Table 2. Characteristics for terminal and penultimate internodes of 100 Ascophyllum fronds (means) from the harvested and from the unharvested area at Rathcunningham

\begin{tabular}{|lccccc|}
\hline & \multicolumn{2}{c}{ Cut } & \multicolumn{2}{c|}{ Uncut } \\
& $77-8$ & $78-9$ & & $77-8$ & $78-9$ \\
\hline Internode length (cm) & 15.2 & 13.3 & 10.5 & 9.8 \\
Dichotomies per internode & 1.81 & 1.70 & 1.08 & 0.95 \\
Laterals per internode & 3.33 & 0.43 & 0.23 & 0.06 \\
\hline
\end{tabular}

The cut area Ascophyllum showed considerably greater growth (Table 2) in terms of internode length and number of lateral branches produced since cutting. The 78-9 lateral figures must be treated with caution owing to the stage of development at time of sampling. F-tests showed dichotomy means which were not significantly different whereas all other values were above the $0.1 \%$ points.

There were significantly more limpets per boulder in the cut area $\bar{x}_{c}=1.11$, $\left.\bar{x}_{u}=0.66, d=2.64, p<0.01\right)$ and they were of smaller average size $\left(\bar{x}_{c}=41.5\right.$, $\bar{x}_{u}=45.6 \mathrm{~mm}, d=3.74 p<0.001$ ). Graphical analysis (Fig. 2) did not lead to clear interpretation of the size structure and growth rate of the populations in the cut and uncut areas in particular the 3 rd age group could not be defined. There was no difference in mean distance of limpets from Ascophyllum holdfasts $\left(\bar{x}_{c}=17.6, \bar{x}_{u}=16.0 \mathrm{~cm}, \mathrm{n}\right.$. s.). The micro-algae scrapes on Patella inhabited or uninhabited boulders showed both that there was significantly more chlorophyll on Patella, uninhabited boulders and on the surface of "cut" boulders (for $\mathrm{Chl}_{\mathrm{a}}=6.36 \mathrm{cf}$. $0.66 \mu \mathrm{g} / \mathrm{cm}^{2}, F=323.8, p<0.001$ and 3.87 cf. $3.05, F=6.92, p<0.05$ respectively). The production and/or settlement rate of 


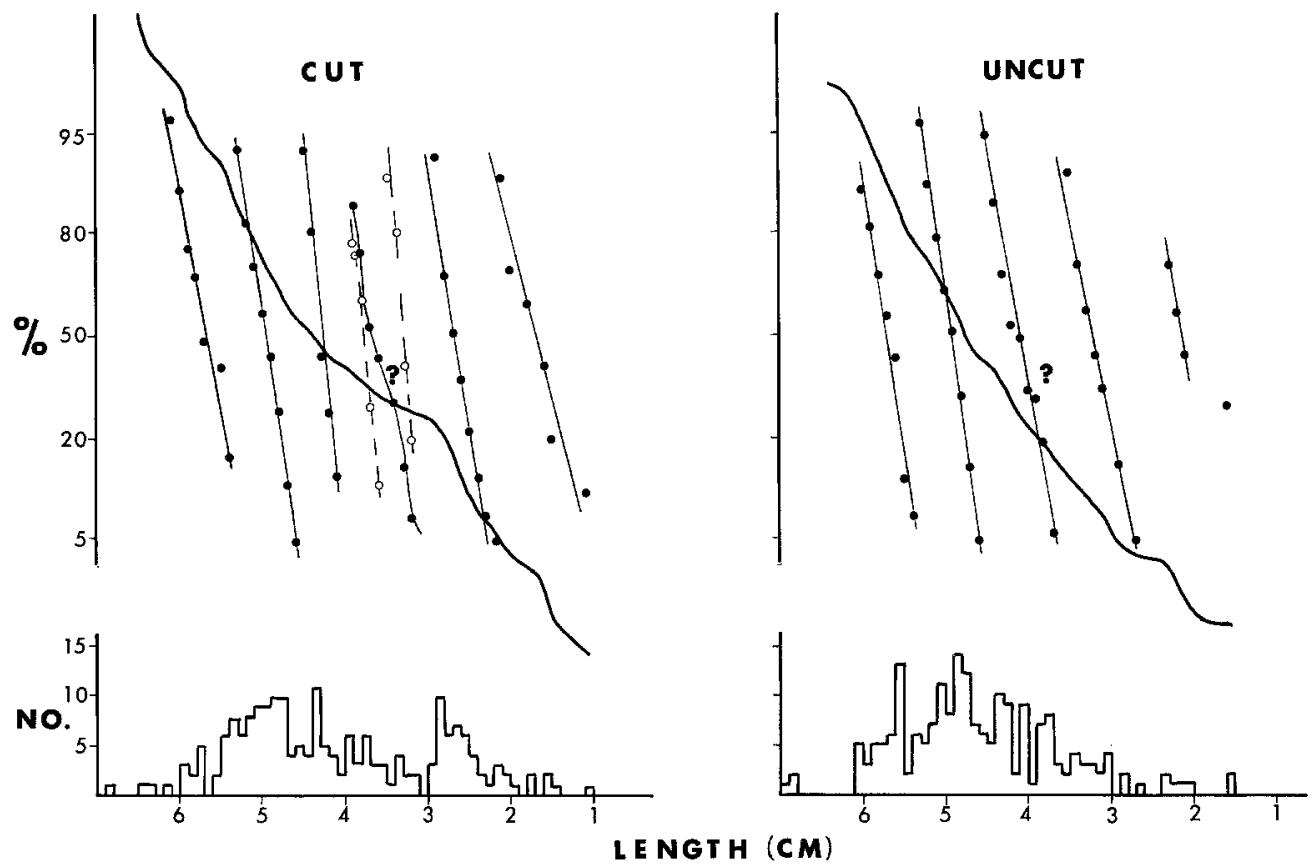

Fig. 2. Frequency distribution of Patella vulgata populations from the Ascophyllum harvested and unharvested areas of the Rathcunningham shore. Histograms show size distribution at 1-mm intervals of length. Upper graphs show cumulative percentage and possible age classes plotted on arithmetic probability paper

chlorophyll on the test surfaces was however over four times smaller in the cut than the uncut area $\left(\mathrm{Chl}_{a}=\mu \mathrm{g} / \mathrm{cm}^{2}, \bar{x}_{c}=1.00, \bar{x}_{u}=4.51, t=3.73, p<0.05\right)$.

Green colour morphs predominated the Littorina collections from both areas (cut $45 \%$, uncut $75 \%$ ) but yellow forms were commoner in the cut $(33 \%)$ than the uncut area $(11 \%)$. Each form was apparently smaller in the cut area but this could have been a collection artefact; however, this could not have entirely accounted for the high proportion of small yellow winkles in the cut area. Mean opercular widths in cut compared with uncut areas were for green 6.1 and $9.2^{* * *}$, yellow 3.7 and $5.2^{* *}$ and brown 8.7 and $9.8^{*} \mathrm{~mm}$.

There was no significant difference in Carcinus frequency or density. Twenty-two percent of cut area boulders sheltered crabs ( 0.94 per boulder). Uncut frequency was twenty percent with 0.76 density.

The sediment analysis gave median grain sizes of 460,350 and $282 \mu \mathrm{m}$ in the cut area and 363, 136 and $153 \mu \mathrm{m}$ in the uncut area, a significant difference although the first and third uncut samples contained two and one fairly large pebbles. Cumulative plots omitting the $<2000-\mu \mathrm{m}$ fraction are shown in Figure 3. These give a mean grain size of 353 and $169 \mu \mathrm{m}$ for the cut and uncut areas $(F=8.79, \mathrm{p}<0.05)$. This difference stems mainly from the smaller percentage of particles $<250 \mu \mathrm{m}$ in the cut area $(F=24.48 p<$ 0.01). The only significant difference in sediment meiofauna expressed as means for the cut $(c)$ and uncut $(u)$ area was in the number of crustaceans found per site $\left(\bar{x}_{c}=44.3\right.$, 


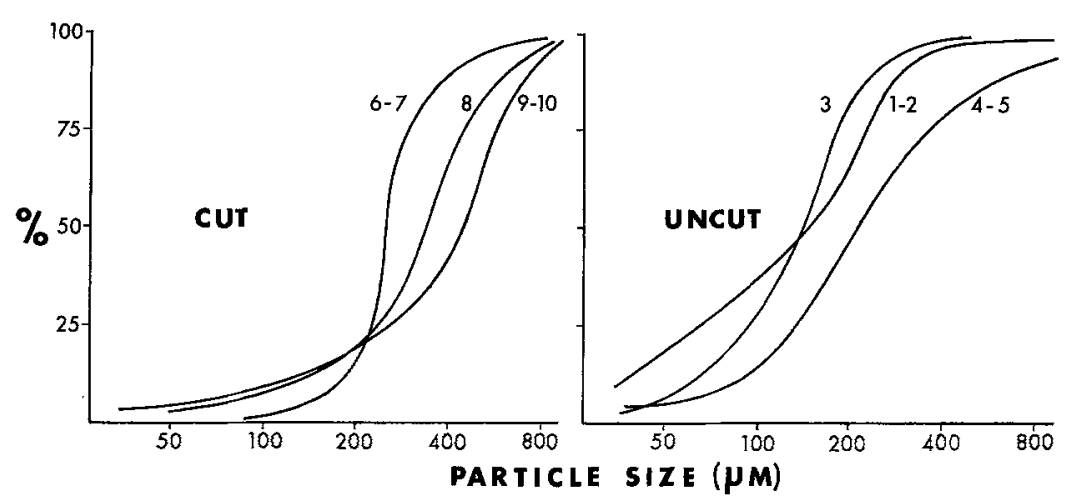

Fig. 3. Granulometry of sediment samples from the harvested and unharvested areas at Rathcunningham. 2000- $\mu \mathrm{m}$ fraction is omitted. For transect positions see Figure 1

$\bar{x}_{u}=10.3, F=22.6, p<0.01$ ), the mean totals for all taxa being 302.3 and 241.3 , respectively $(F=1.20, \mathrm{n}$. s.).

In the Rhodochorton study the average weights $(\mathrm{g})$ per $10-\times 10-\mathrm{cm}$ area of each boulder for algae $\left(\bar{x}_{c}=4.73, \bar{x}_{u}=2.37\right)$, sediment $(86.9,45.6)$ and worms $(1.36,0.3)$ were all higher in the cut area but only the worm values reached significance $(F=6.4, p<$ 0.05). Significant figures in Student $t$-tests were the greater total and greater average worm weights from the cut area; these weights were significantly regressed with sediment volume and sediment weight, respectively $(r=0.72, p<0.1 ; r=0.84, p<$ $0.1)$.

Mean values derived from the boulder data are presented in Table 3. This shows the boulder habitable area to have been broadly similar although there was somewhat less undersurface on the cut area boulders. The discrepancies between total habitable areas and slope category figures arise from incomplete data (failure to record all distances between transect lines on one cut and two uncut boulders). The $\%$ cover data was very variable, hence many of the apparently large differences between cut and uncut areas were not statistically significant when variances were compared. The amount of bare rock on upper surfaces, the abundance of Cladophora, Halichondria on steep slopes and bryozoans and Verruca on the light underslopes are the main examples.

The apparently significant figures for Mytilus are due to its near absence from any of the cut area boulders examined although it was found in more general collection. There were clear and significant differences however between sponge cover on the underfaces of the cut and uncut boulders and in the abundance of Balanus crenatus on the light underslopes in the two areas. A general impoverishment of the underboulder fauna in the cut area is shown by the total $\%$ cover figures which are less by about one eighth of the total possible cover on steep slopes (that is by over a third of actual uncut area cover) and by about one third of total cover on light slopes (one quarter actual uncut cover).

The counts of larger animals (number per $0.1 \mathrm{~m}^{2}$ ) on upper and undersurfaces only showed significant differences in Mytilus $\left(\bar{x}_{c}=0, \bar{x}_{u}=3.7, F=17.8, p<0.001\right)$ and dead Balanus $\left(\bar{x}_{c}=2.0, \bar{x}_{u}=20.4, F=11.32, p<0.05\right)$ both on light underslopes. The mean number of live Balanus crenatus per boulder on all slopes was 11.2 and 116.3 in cut and uncut areas $(F=7.4 p<0.05)$ although the density values ( 3 and 33$)$ were not 
Table 3. Habitable area $\left(\mathrm{cm}^{2}\right)$ and mean \% cover of boulders from harvested and unharvested areas of Ascophyllum at Rathcunningham. Surface category (see text) $\mathrm{T}$, top; V, vertical; $\mathrm{S}_{\text {, steep }} \mathrm{L}_{\mathrm{t}}$ light. $\mathrm{P}$, peripheral cover. ${ }^{*} p<0.05,{ }^{* *} p<0.01$

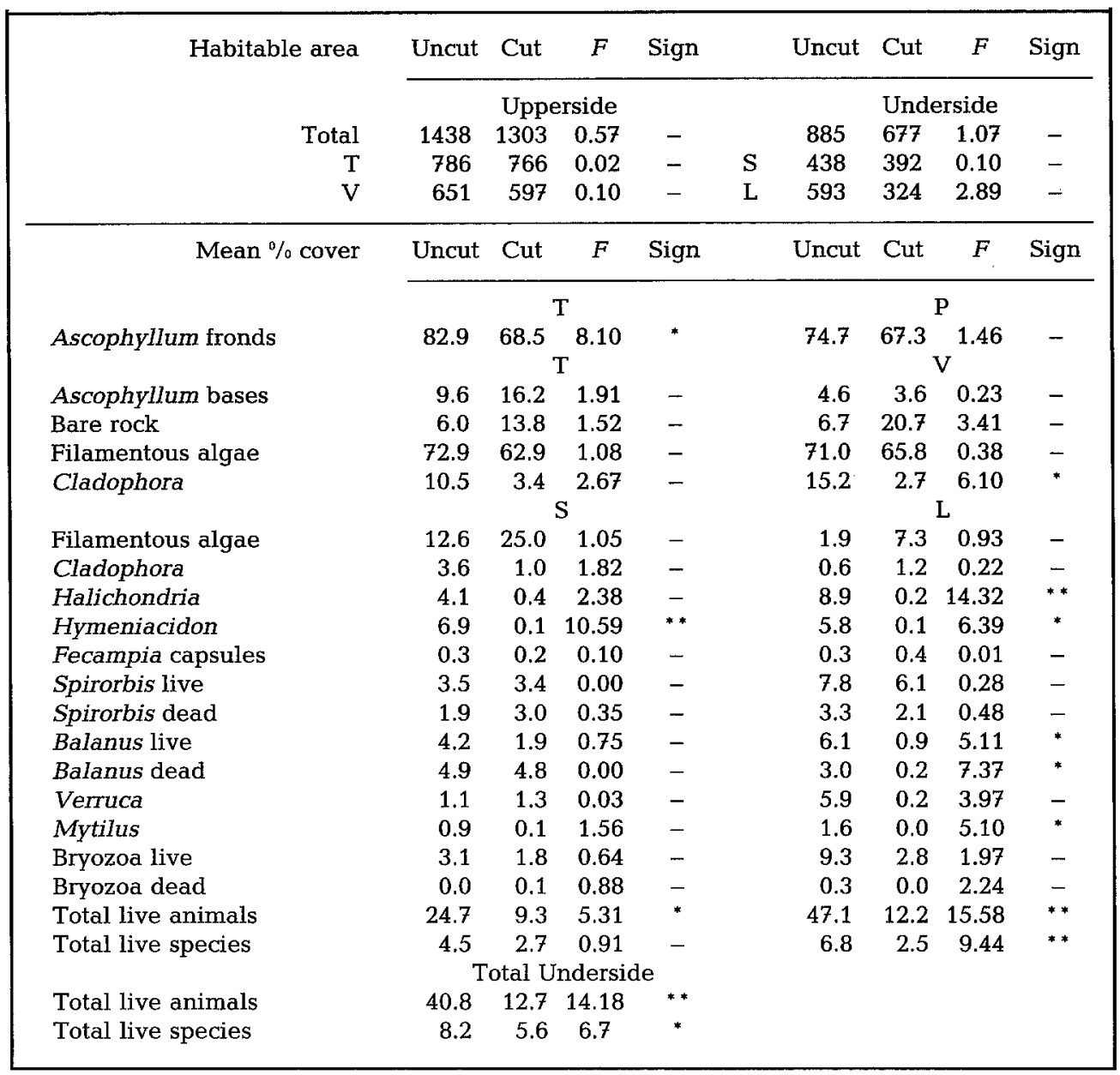

significantly different. The density of Spirorbis aff. tridentatus was virtually identical on the vertical slopes where it occurred in relative abundance in both areas $\left(\bar{x}_{c}=87.6\right.$, $\bar{x}_{u}=88.9$ ).

\section{DISCUSSION}

Although the regrowth and recolonization by Ascophyllum after cutting or shore clearance has been the subject of a number of studies (e. g. Baardseth, 1955; Printz, 1959) there is very little published information on any other effects its removal might have on shore ecology. Lewis (1964) mentions redevelopment of lower shore algal turf and death of Lithothamnion, Balanus crenatus and Pomatoceros but this has not been quantified. Experimental or accidental clearance from the shore of whole biota (North et al, 1964; 
Smith, 1968) or of species other than Ascophyllum (Southward, 1964) indicate possible effects but these cited works are among the very few where observations have been continued into the recovery period.

The more rapid growth of the Ascophyllum internodes following cutting agrees with the studies mentioned, presumably the increased bushiness will lead to further shading of the boulder surface. This and/or abrasion should decrease the present higher cover of Enteromorpha and Ulva. Further examination of our results by comparison of boulders with greater or smaller than mean Ascophyllum cover (regardless of whether from cut or uncut areas) indicates this process has already begun with filamentous algae on the top surface of boulders $\left(\bar{x}_{>} 54 \%, \bar{x}_{<} 72 \%\right)$ since the corresponding differences between cut and uncut areas (Table 2) are much narrower, whereas they are equal or greater on vertical or steep slopes. In the cut area there is a possibly just significant negative correlation between algal cover on the top surfaces with Ascophyllum top cover $(r=-0.56, p<0.1)$ and Ascophyllum peripheral cover $(r=-0.67, p<0.1)$.

It is possible that the difficulty in interpreting the Patella graphs (Fig. 2) is due to perturbation in growth following the change in shore conditions after harvesting. If this were so the "problematical" third age group may well correspond to the 1976 recruited population. The greater boulder surface chlorophyll in the cut area is interpreted as a reflection of higher productivity resulting from increased illumination; the higher chlorophyll "settlement" rate in the uncut areas is due to shelter by the Ascophyllum allowing greater settlement and/or the greater supply of Ascophyllum spores (since there were many more active conceptacles in the uncut area).

We offer no explanation for the apparent Littorina differences. Selective predation could affect both colour morph ratio and average size but clearly this can be neither accepted or rejected on present evidence.

The Carcinus data indicated no present difference in this important component of the shore system.

The crustacean meiofauna chiefly consisted of harpacticoids; the higher number in the cut area is likely to result from the coarser grain size and associated better oxygenation of the sediment. The comparative lack of finer particles in the cut area must result from different hydrological conditions. Harvesting weed will have removed much of the damping effect of fronds on water turbulence thus leading to resuspension of finer material. This then presumably becomes available elsewhere and might account for the thicker Rhodochorton mats on suitable boulders in the cut area.

As mentioned, the boulder $\%$ cover data has been re-analysed to compare boulders with greater or less than mean Ascophyllum peripheral cover (9 and 11 boulders respectively) but no significant $F$ values were found for any fauna. The differences in the cut and uncut areas are therefore not just due to the p r e s e n t abundance of Ascophyllum but must reflect past history. A similar analysis but using the ten most covered boulders versus the ten least also gave no significant values except in the case of Spirorbis (\% live cover on steep slopes $\bar{x}_{>} 5.4, \bar{x}_{<} 1.2, F 7.4 p<0.01$; live and dead per 0.1 $\mathrm{m}^{2}$ on vertical faces $\bar{x}_{>} 158$ and $54.9 \bar{x}_{<} 10.8$ and 0.4 respectively, $F=4.4$ and 4.9 , both $p$ $<0.01$ ). Using data from all boulders numbers of both live and dead Spirorbis on steep slopes were positively correlated with peripheral Ascophyllum cover, with combined numbers of live and dead $r=0.49(p<0.05)$. Splitting the data from uncut and cut areas the former showed no significant regression $(r=0.20)$ but the latter $(r=0.88 p<0.005)$ 
was nearly twice the overall value. Thus it appears that Ascophyllum cover was particularly important to this species - the uncut cover being sufficient to its needs but the cut area regrowth not yet supplying a sufficient resource (shelter from desiccation?) for cover not to be a limiting factor. The similarity of the "cut" and "uncut" Spirorbis values seems to contradict this difference however and it must be assumed that some advantageous factor of the cut area (increased water movement for feeding?) is balancing out the disadvantage of lesser weed cover.

The low Balanus numbers in the cut area are attributed to death following the weed harvesting. However, the number of dead barnacles including base "scars" per boulder was in fact smaller in the cut area $\left(\bar{x}_{C}=13.1, \bar{x}_{\mathrm{u}}=32.2\right)$; the live-to-dead ratios in the cut and uncut areas were 3.61 and $0.85: 1$ respectively. It must follow therefore that Balanus bases had not persisted over the $2 \frac{1}{2}$ year period since cutting.

The sponges emerge as the two animal species mostly clearly affected by the harvesting (a conclusion supported by photographs and general observation of the situation soon after cutting). This reflects the general limitation, through physiological exclusion, of intertidal colonial animals to cryptic environments (Jackson, 1977). These two species and the encrusting bryozoans (mainly Schizoporella unicornis) account for much of the difference of $\%$ underboulder cover especially on the light slopes (their joint contribution is $\bar{x}_{C}=3 \%, \bar{x}_{u}=24 \%, F=12.97 p<0.01$ ).

\section{CONCLUSION}

It is clear from our observations that the effects of harvesting Ascophyllum persisted over the $2 \frac{1 / 2}{2}$ year period. In the cut area: (1) Growth rate of Ascophyllum had increased but shore cover was still less. (2) Cover by green algae and Fucus vesiculosus had increased. (3) Patella density had increased and mean size decreased. (4) Microalgal cover of boulders had increased. (5) Sediment median diameter had increased. (6) Halichondria, Hymeniacidon and to a lesser extent Balanus crenatus had decreasesd. (7) Underboulder fauna remained impoverished by a factor of between one- and two-thirds.

Thus even with this small scale cutting there has been noticeable ecological change. Larger scale commercial harvesting would probably have a greater effect through the alteration of populations over a wider area with consequent decline in larval supply, increase in sediment mobility and loss of organic material from the inshore system. Such impact cannot be ignored in areas, such as Strangford Lough, where it is intended that conservation of the natural environment be given priority. It is highly important to our long-term needs that the exploitation of marine resources is planned both on a sound economic and scientific basis. The conservation of some areas in a relatively pristine state so that the routes and rates of natural processes can be studied must be accepted as an integral part of such rational planning.

Acknowledgements. Our thanks are due to most (if not all) of the Q. U. B. 1979 Marine Biology Class. The help, hospitality and forebearance of Senator Myles Staunton and staff of Clew Bay Seaweeds is gratefully acknowledged. 


\section{LITERATURE CITED}

Baardseth, E., 1955. Regrowth of Ascophyllum nodosum after harvesting. Inst. Indust. Res. Standards, Dublin, $67 \mathrm{pp}$.

Cassie, R. M., 1954. Some uses of probability paper in the analysis of size frequency distributions. Aust. J. mar. Freshw. Res., 5, 513-522.

Jackson, J. B. C., 1977. Competition on marine hard substrata: the adaptive significance of solitary and colonial strategies. - Am. Nat. 111, 743-767.

Jeffrey, S. W. \& Humphrey, G. F., 1975: New spectrophotometric equations for determining chlorophylls $\mathrm{a}, \mathrm{b}, \mathrm{c}_{1}$ and $\mathrm{c}_{2}$ in higher plants, algae and natural phytoplankton. - Biochem. Physiol. Pflanzen 167, 191-194.

Lewis, J. R., 1964. The ecology of rocky shores. English Univ. Press, London, 323 pp.

North, W. J., Neushul, M. \& Clendenning, K. A., 1964. Successive biological changes observed in a marine cove exposed to a large spillage of mineral oil. - Symp. Pollut. mar. Microorg. Prod. Petrol. Monaco 1964, 335-354.

Printz, H., 1959. Investigations of the failure of recuperation and repopulation in cropped AscophylIum areas. - Avh. norske VidenskAkad. Oslo 3, 1-15.

Smith, J. E., 1968. "Torrey Canyon" pollution and marine life. Cambridge University Press, 196 pp.

Southward, A. J., 1964. Limpet grazing and the control of vegetation on rocky shores. - Symp. Br. ecol. Soc. 4, 265-273.

Strangford Lough Working Group, 1978. Report to the Department of the Environment. Dept. Environment, (Northern Ireland), Belfast, $16 \mathrm{pp}$. 